\title{
PRODUÇÃO CIENTÍFICA EM SAÚDE AUDITIVA NO BRASIL: ANÁLISE DO PERÍODO DE 2000 A 2010
}

\author{
Scientific production in hearing health in Brazil: \\ analysis of the period from 2000 to 2010
}

\author{
Kléber Rangel Silva ${ }^{(1)}$, Marcela Cristina Ferreira ${ }^{(2)}$, Ana Cristina de Oliveira Mares Guia ${ }^{(3)}$, \\ Raimundo de Oliveira Neto ${ }^{(4)}$, Stela Maris Aguiar Lemos ${ }^{(5)}$
}

\begin{abstract}
RESUMO
Este estudo tem como tema a análise do estado da arte sobre saúde auditiva no Brasil e a investigação da construção da produção científica nesta área. O objetivo é descrever, analisar e construir a linha histórica da produção científica em saúde auditiva no Brasil, no período de 2000 a 2010, tendo como referência a implantação, desenvolvimento e avaliação da política de Saúde Auditiva no contexto do Sistema Único de Saúde (SUS). As primeiras publicações encontradas são do ano de 2005. Com o passar dos anos, principalmente nos dois últimos, o número de publicações cresceu gradativamente. O eixo temático com maior número de artigos relacionados foi Usuários. O tema avaliação, com enfoque na satisfação do usuário, foi o mais abordado. Os temas gestão e capacitação de profissionais também foram recorrentes.
\end{abstract}

DESCRITORES: Saúde Pública; Política de Saúde; Audição

\section{INTRODUÇÃO}

Em novembro do ano 2000 o Ministério da Saúde publicou a Portaria MS/SAS 432. Esse foi o

(1) Fonoaudiólogo; Servidor público da Secretaria de Estado da Saúde de Minas Gerais - SES/MG, Belo Horizonte, Minas Gerais, Brasil; Especialização em Saúde Pública pela ENSP/FIOCRUZ.

(2) Graduanda em Fonoaudiologia da Universidade Federal de Minas Gerais - UFMG, Belo Horizonte, Minas Gerais, Brasil.

(3) Fonoaudióloga do serviço de atenção à saúde auditiva do Hospital das Clínicas da UFMG,HC-UFMG, Belo Horizonte, Minas Gerais, Brasil; Especialização em Audiologia pela Faculdades Metodistas Integradas Izabela Hendrix FAMIH.

(4) Fonoaudiólogo; Servidor público da Secretaria Municipal de Saúde de Belo Horizonte - SMS/BH, Belo Horizonte, Minas Gerais, Brasil; Pós-graduado em Audiologia Clínica pelo Instituto Brasileiro de Medicina de Reabilitação - Rio de Janeiro - IBMR-RJ.

(5) Fonoaudióloga; Professora Adjunto do Departamento de Fonoaudiologia da Universidade Federal de Minas Gerais UFMG, Belo Horizonte, Minas Gerais, Brasil; Doutora em Ciências pela Universidade Federal de São Paulo.

Fonte de auxílio: Edital FAPEMIG 24/2009 - Fundação de Amparo à Pesquisa de Minas Gerais.

Conflito de interesses: inexistente primeiro passo para a criação da Política Nacional de Atenção à Saúde Auditiva, uma vez que determinou alguns avanços, como a formação de equipe multidisciplinar, a organização do serviço voltada especificamente para os pacientes da saúde auditiva, a utilização de nomenclatura mais atualizada e o acompanhamento fonoaudiológico atrelado à concessão do Aparelho de Amplificação Sonora Individual (AASI). Essa política foi definitivamente instituída com a publicação da Portaria 2.073/ GM em setembro de 2004, que teve como um dos pontos chaves a consolidação, organização e oficialização da prática fonoaudiológica dentro do Sistema Público de Saúde no campo da Saúde Auditiva, designando o profissional fonoaudiólogo como o responsável pelo diagnóstico audiológico, seleção e adaptação de AASI e acompanhamento dos pacientes com deficiência auditiva. A portaria estabeleceu a organização da implantação da nova política de forma articulada entre as três esferas de poder (Federal, Estadual e Municipal) e atendeu às demandas de promoção, prevenção e reabilitação'.

Neste contexto, o usuário teve garantido seu direito à atenção integral, multiprofissional/ interdisciplinar e continuada em saúde auditiva, 
abrangendo todas as linhas de cuidado (avaliação e diagnóstico, seleção e adaptação de AASI, acompanhamento, terapia fonoaudiológica, reavaliação diagnóstica, reposição de AASI e molde auricular). Essas práticas visaram promover ao usuário uma melhoria não só em sua audição, mas em sua comunicação geral e qualidade de vida ${ }^{1,2}$.

Ainda no ano de 2004, no mês de outubro, foram publicadas outras duas Portarias, MS/SAS 587 e MS/SAS 589, que estabeleceram o credenciamento dos Serviços de Atenção à Saúde Auditiva e as atribuições dos três diferentes níveis de complexidade do sistema. A Atenção Básica é responsável por ações coletivas ou individuais, que visem a promoção da saúde auditiva, a prevenção e a identificação precoce da deficiência auditiva, além da realização de atividades informativas e educativas. Os serviços de Média Complexidade são responsáveis pelo diagnóstico e terapia fonoaudiológica, oferecendo estrutura física e profissional adequadas ao atendimento de indivíduos com risco ou suspeita de perda auditiva e com a deficiência auditiva já diagnosticada, excluindo crianças com idade inferior a três anos, além de triagem e monitoramento da audição de neonatos e escolares. A equipe é integrada por médicos otorrinolaringologistas, fonoaudiólogos, assistentes sociais e psicólogos. Os de Alta Complexidade têm as mesmas atribuições dos de Média Complexidade, entretanto tratam também da avaliação e diagnóstico de crianças com menos de três anos de idade e de pacientes com afecções associadas de qualquer natureza. Além disso, devem contar com uma equipe multiprofissional maior que a encontrada na Média Complexidade, dispondo também de médicos neurologistas e pediatras ${ }^{3,4}$.

Por meio deste estudo, foi possível fazer um levantamento da produção científica sobre saúde auditiva no Brasil. Por ser esta uma política recente, considera-se importante uma análise reflexiva da literatura, a fim de avaliar o que vem sendo feito desde a implantação da política de saúde auditiva. Com isso, pretende-se investigar a construção da produção científica na área, sistematizar esse conhecimento e construir a linha histórica da produção científica encontrada, tendo como referencial a Política Nacional de Atenção à Saúde Auditiva.

O objetivo é descrever, analisar e construir a linha histórica da produção científica em saúde auditiva no Brasil, no período de 2000 a 2010, tendo como referência a implantação, desenvolvimento e avaliação da política de Saúde Auditiva no contexto do Sistema Único de Saúde (SUS).

\section{MÉTODO}

Trata-se de revisão integrativa de literatura, para a qual foi realizado um levantamento bibliográfico nas bases de dados do Portal Capes, Bireme e Scielo. Os artigos foram acessados até a data limite de dezembro de 2010. As palavras-chave utilizadas na pesquisa foram saúde pública, audiologia e saúde auditiva.

Os critérios de inclusão dos artigos no estudo foram apresentar conteúdo relacionado à Política de Atenção à Saúde Auditiva, estar disponível na íntegra e relacionar-se a um dos três eixos temáticos estabelecidos para a análise dos artigos, a saber:

Eixo temático Usuários: artigos relacionados ao estudo do perfil epidemiológico e sociodemográfico, adesão e perspectiva do usuário quanto à qualidade da assistência em saúde auditiva e ao tema saúde auditiva.

Eixo temático Profissionais: artigos relacionados ao estudo do perfil sociodemográfico e técnico, instrumentalização/capacitação de fonoaudiólogos e demais profissionais de saúde envolvidos na implantação, gestão, organização e assistência em saúde auditiva.

Eixo temático Serviço: artigos relacionados à descrição da implantação, organização, gestão e avaliação de serviços de saúde auditiva, descrição da construção de indicadores e de protocolos de atendimento e acompanhamento.

Ao final, foram selecionados e analisados 21 artigos para o presente estudo, publicados de 2005 a 2010.

A análise dos dados coletados foi realizada de forma integrativa, em duas etapas. Na primeira, foram identificados os dados referenciais do artigo (autoria, objetivo, metodologia e resultados principais). Na segunda etapa ocorreu a análise crítica dos artigos e discussão quanto ao "estado da arte" das publicações dentro dos respectivos eixos temáticos (usuários, profissionais ou serviço), estabeleceu-se a cronologia das publicações, análise dos principais achados e avanços evidenciados pelos estudos.

\section{REVISÃO DE LITERATURA}

Os artigos relacionados para este estudo foram distribuídos, de acordo com a temática abordada, em três diferentes eixos - Usuários, Profissionais e Serviço. Do total de 21, 13 artigos (62\%) se relacionam ao eixo temático: Usuários; três artigos (14\%) ao eixo temático: Profissionais; e cinco (24\%) ao eixo temático: Serviço. 
A Figura 1 mostra a cronologia das publicações utilizadas neste estudo. Nota-se um aumento progressivo do número de publicações nos dois últimos anos, passando de 2 publicações em 2005 para 15 nos anos de 2009 e 2010; assim como aumentou a variedade dos temas abordados nos estudos com a inserção das temáticas de acesso e perfil do usuário ao serviço, avaliação dos serviços, criação de indicadores em saúde auditiva e capacitação do profissional de saúde em saúde auditiva.

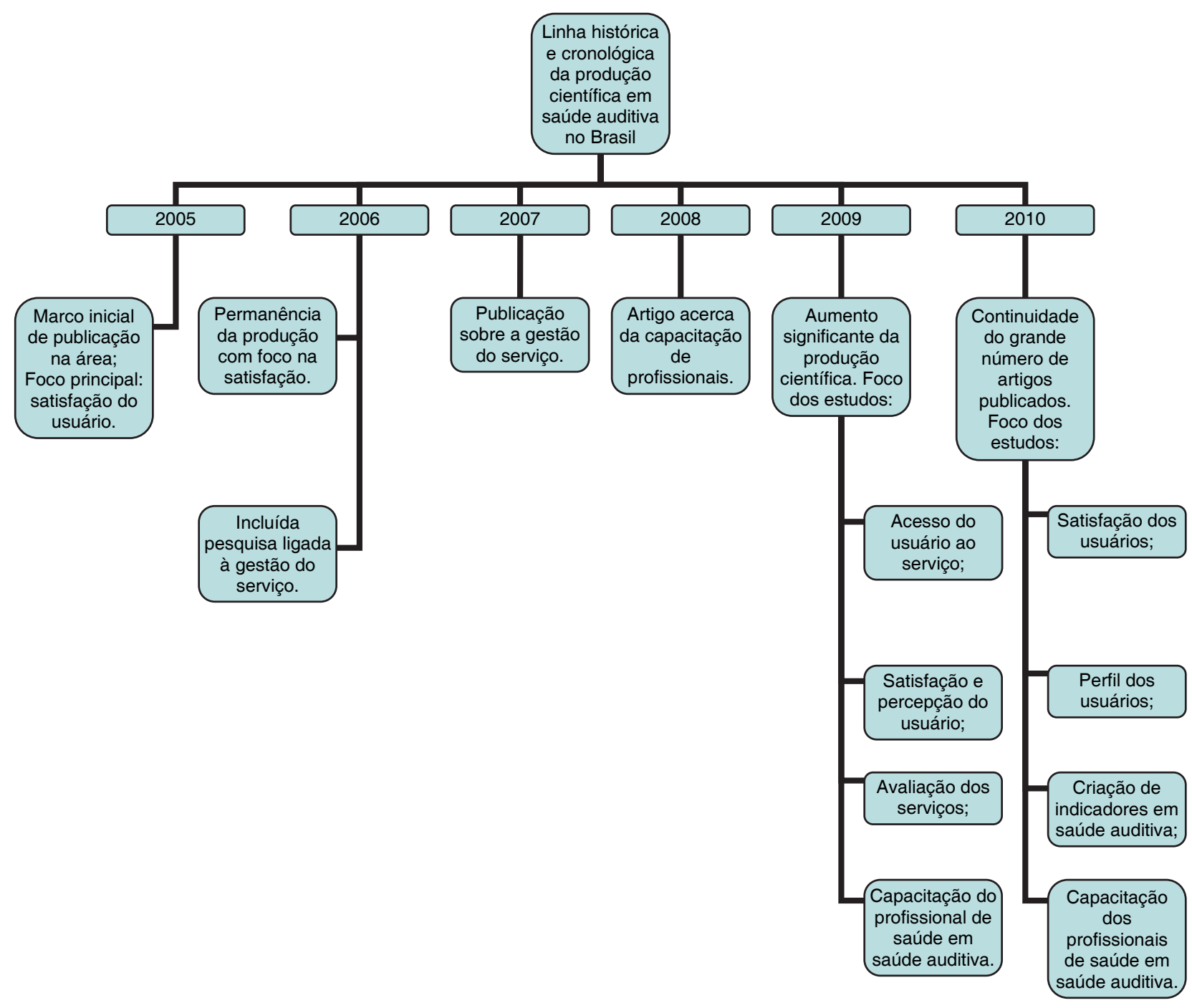

Figura 1 - Linha histórica e cronológica da produção científica em saúde auditiva no Brasil 
Na Figura 2 estão descritos os artigos relacionados ao eixo temático Usuários. Dos 13 artigos encontrados, dois discorrem sobre o acesso da população deficiente auditiva ao serviço de atenção básica ${ }^{5,6}$; dois descrevem segmentos da população que são atendidos pelo Programa de Atenção à
Saúde Auditiva 7,8 ; e nove apresentam como tema central a avaliação do serviço de Saúde Auditiva do ponto de vista do usuário ${ }^{9-17}$. Dentro do tema avaliação, o aspecto mais valorizado é a satisfação do usuário, sendo abordado em sete dos nove artigos.

\begin{tabular}{|c|c|c|c|c|}
\hline Autor e ano & Título & Objetivo & Metodologia & Resultados Principais \\
\hline $\begin{array}{l}\text { Á lanni e } \\
\text { P C A Pereira - } \\
2009\end{array}$ & $\begin{array}{l}\text { Acesso da } \\
\text { Comunidade Surda à } \\
\text { rede básica de Saúde }\end{array}$ & $\begin{array}{l}\text { Apresentar as } \\
\text { dificuldades do acesso } \\
\text { da população surda aos } \\
\text { serviços de Atenção } \\
\text { Básica e a percepção } \\
\text { dos gerentes de } \\
\text { unidades de saúde a } \\
\text { esse respeito. }\end{array}$ & $\begin{array}{l}\text { O projeto foi realizado } \\
\text { em duas etapas: na } \\
\text { primeira foram realizadas } \\
\text { quatro entrevistas } \\
\text { com informantes- } \\
\text { chave pertencentes à } \\
\text { Comunidade Surda e } \\
\text { membros representativos } \\
\text { do governo; na segunda } \\
\text { etapa, aplicou-se um } \\
\text { questionário para } 21 \\
\text { gerentes de Unidades } \\
\text { Básicas de Saúde (UBS) } \\
\text { de uma sub-regional do } \\
\text { Município de São Paulo. }\end{array}$ & $\begin{array}{l}\text { - Barreiras comunicacionais; } \\
\text { - Escassez de insumos } \\
\text { Tecnológicos; } \\
\text { - Políticas Públicas aquém do } \\
\text { necessário; } \\
\text { - Funcionários não } \\
\text { capacitados para atender as } \\
\text { demandas dessa população e } \\
\text { ausência de intérpretes; } \\
\text { - Os gerentes das UBS } \\
\text { demonstram desconforto } \\
\text { com o tema e alegam falta de } \\
\text { recursos para desenvolver } \\
\text { melhorias. }\end{array}$ \\
\hline $\begin{array}{l}\text { D B Freire, } \\
\text { L P Gigante, } \\
\text { J U Béria, } \\
\text { L S Palazzo, } \\
\text { A C L Figueiredo, } \\
\text { B C W Raymann - } \\
2009\end{array}$ & $\begin{array}{l}\text { Acesso de pessoas } \\
\text { defi cientes auditivas } \\
\text { a serviços de saúde } \\
\text { em cidade do Sul do } \\
\text { Brasil }\end{array}$ & $\begin{array}{l}\text { Comparar o acesso dos } \\
\text { portadores de deficiência } \\
\text { auditiva incapacitante } \\
\text { a serviços assistenciais } \\
\text { e de prevenção com o } \\
\text { acesso dos ouvintes. }\end{array}$ & $\begin{array}{l}\text { O estudo transversal, } \\
\text { realizado na cidade } \\
\text { de Canoas/RS. Dados } \\
\text { coletados entre novembro } \\
\text { de } 2002 \text { a julho de } \\
\text { 2003. Nos domicílios } \\
\text { visitados, foi aplicado } \\
\text { um questionário aos } \\
\text { moradores de } 14 \text { anos } \\
\text { ou mais. Utilizou-se o } \\
\text { protocolo de pesquisa } \\
\text { de distúrbios de orelha e } \\
\text { audição da OMS. }\end{array}$ & \begin{tabular}{|l} 
Foi avaliado o efeito de ser \\
portador de deficiência auditiva \\
incapacitante sobre cada uma \\
das variáveis. Foi constatado \\
que os deficientes auditivos \\
apresentam maiores escores \\
referentes a consulta nos dois \\
meses anteriores à entrevista; \\
consultas em hospital ou em \\
outra cidade; prevalência de \\
internação hospitalar no ano \\
anterior à entrevista; e escores \\
menores em relação à uso de \\
preservativo na última relação \\
sexual; realização de auto- \\
exame das mamas. \\
\end{tabular} \\
\hline $\begin{array}{l}\text { M E Armigliato, } \\
\text { et al. }-2010\end{array}$ & $\begin{array}{l}\text { Avaliação de serviços } \\
\text { de saúde auditiva } \\
\text { sob a perspectiva do } \\
\text { usuário: proposta de } \\
\text { instrumento }\end{array}$ & \begin{tabular}{|l} 
Verificar a aplicabilidade \\
de um questionário de \\
avaliação de serviço de \\
saúde auditiva, sob a \\
perspectiva do usuário, \\
elaborado para ser \\
aplicado nos serviços de \\
saúde auditiva do SUS.
\end{tabular} & \begin{tabular}{|l|} 
Foi aplicado um \\
questionário com \\
18 questões nas \\
dimensões: acesso ao \\
serviço, avaliação da \\
audição, atendimento \\
personalizado, benefício \\
para família, comunicação \\
e informação, e \\
competência profissional. \\
Cada questão foi \\
apresentada em escala \\
graduada de cinco \\
pontos. 53 pacientes \\
(ou responsável/ \\
acompanhante) \\
responderam ao \\
questionário.
\end{tabular} & $\begin{array}{l}\text { Os escores foram: acesso - } \\
62,25 \% \text {, avaliação da } \\
\text { audição - } 85,96 \% \text {, } \\
\text { atendimento personalizado - } \\
82,05 \% \text {, benefício para família } \\
-68,57 \% \text {, comunicação } \\
\text { e informação - } 79,13 \% \text {, } \\
\text { competência profissional - } \\
97,39 \% \text { e escore total - } \\
70,65 \% \text {. Pacientes com menor } \\
\text { nível de escolaridade, menor } \\
\text { tempo de atendimento no } \\
\text { serviço e os já adaptados } \\
\text { apresentaram melhores } \\
\text { resultados no escore total do } \\
\text { questionário. }\end{array}$ \\
\hline
\end{tabular}




\begin{tabular}{|c|c|c|c|c|}
\hline Autor e ano & Título & Objetivo & Metodologia & Resultados Principais \\
\hline $\begin{array}{l}\text { I M Fialho, } \\
\text { D Bortoli, } \\
\text { G G Mendonça, } \\
\text { D F Pagnosim, } \\
\text { A S Scholze - } \\
2009\end{array}$ & $\begin{array}{l}\text { Percepção de idosos } \\
\text { sobre o uso de AASI } \\
\text { Concedido pelo } \\
\text { Sistema Único de } \\
\text { Saúde }\end{array}$ & $\begin{array}{l}\text { Conhecer a percepção } \\
\text { de idosos } \\
\text { sobre uso de AASI } \\
\text { concedido pelo Sistema } \\
\text { Único de Saúde (SUS). }\end{array}$ & $\begin{array}{l}\text { Estudo de caráter } \\
\text { qualitativo. Foram } \\
\text { realizadas entrevistas } \\
\text { semi-estruturadas com } \\
19 \text { idosos, entre } 60 \text { e } 86 \\
\text { anos, com adaptação } \\
\text { binaural e tempo de } \\
\text { uso de AASI entre seis } \\
\text { meses e um ano. As } \\
\text { categorias estabelecidas } \\
\text { foram: dificuldades de } \\
\text { comunicação sem AASI; } \\
\text { o acesso ao AASI e o } \\
\text { processo de adaptação } \\
\text { ao uso; o impacto do uso } \\
\text { do AASI na comunicação. }\end{array}$ & $\begin{array}{l}\text { A maior dificuldade no uso } \\
\text { do AASI está em conversar } \\
\text { em ambientes barulhentos } \\
\text { e no telefone. A maioria dos } \\
\text { entrevistados só teve acesso à } \\
\text { prótese após a implantação do } \\
\text { serviço de saúde auditiva, por } \\
\text { dificuldade financeira. Apesar } \\
\text { das dificuldades da adaptação, } \\
\text { a maioria revelou melhora nas } \\
\text { habilidades comunicativas. }\end{array}$ \\
\hline $\begin{array}{l}\text { F R Santos, } \\
\text { A K S Manfredi, } \\
\text { M L Isaac-2009 }\end{array}$ & $\begin{array}{l}\text { Caracterização da } \\
\text { perda auditiva de } \\
\text { crianças atendidas } \\
\text { em um programa de } \\
\text { saúde auditiva }\end{array}$ & $\begin{array}{l}\text { Caracterizar a perda } \\
\text { auditiva de crianças } \\
\text { avaliadas e atendidas } \\
\text { no Programa de Saúde } \\
\text { Auditiva do Hospital das } \\
\text { Clínicas de Ribeirão } \\
\text { Preto. }\end{array}$ & $\begin{array}{l}\text { Estudo retrospectivo em } \\
\text { uma amostra de } 279 \\
\text { prontuários de crianças na } \\
\text { faixa etária entre } 2 \text { a } 12 \\
\text { anos de idade, atendidas } \\
\text { no período de outubro de } \\
2001 \text { a agosto de } 2005, \\
\text { sendo selecionados para } \\
\text { a análise de resultados } \\
133 \text { casos que tiveram } \\
\text { a confirmação da perda } \\
\text { auditiva. }\end{array}$ & $\begin{array}{l}\text { Predominou a perda auditiva } \\
\text { neurossenssorial, profunda } \\
\text { bilateral. Nos casos unilaterais, } \\
\text { prevaleceu o tipo condutivo } \\
\text { de grau leve. O fator de risco } \\
\text { mais frequente foi a queixa da } \\
\text { família de atraso na aquisição } \\
\text { e desenvolvimento da } \\
\text { linguagem, fala e audição. }\end{array}$ \\
\hline $\begin{array}{l}\text { S M S Griz, } \\
\text { C P Barbosa, } \\
\text { A R A Silva, } \\
\text { M A Ribeiro, } \\
\text { D C Menezes - } \\
2010\end{array}$ & $\begin{array}{l}\text { Aspectos } \\
\text { demográficos e } \\
\text { socioeconômicos } \\
\text { de mães atendidas } \\
\text { em um programa } \\
\text { de triagem auditiva } \\
\text { neonatal }\end{array}$ & $\begin{array}{l}\text { Descrever alguns } \\
\text { aspectos demográficos } \\
\text { e socioeconômicos } \\
\text { de mães de neonatos } \\
\text { e lactentes atendidos } \\
\text { no serviço de Triagem } \\
\text { Auditiva Neonatal, do } \\
\text { Hospital das Clínicas, } \\
\text { da Universidade } \\
\text { Federal Pernambuco } \\
\text { (HC-UFPE), nascidos no } \\
\text { ano de 2007. }\end{array}$ & $\begin{array}{l}\text { A coleta de dados foi } \\
\text { constituída por leitura e } \\
\text { digitação das informações } \\
\text { contidas no banco de } \\
\text { dados referente ao } \\
\text { programa de Triagem } \\
\text { Auditiva Neonatal do HC- } \\
\text { UFPE. Participaram da } \\
\text { pesquisa } 1.193 \text { mães. }\end{array}$ & $\begin{array}{l}\text { A maioria das mães tinha } \\
\text { entre } 20 \text { e } 29 \text { anos e eram } \\
\text { casadas, possuíam 1o grau } \\
\text { incompleto, eram donas de } \\
\text { casa e/ou não possuíam } \\
\text { renda pessoal. A população } \\
\text { estudada encontra-se em } \\
\text { condições consideradas } \\
\text { desfavoráveis para a saúde e } \\
\text { desenvolvimento global dos } \\
\text { neonatos e lactentes. }\end{array}$ \\
\hline $\begin{array}{l}\text { R D Angeli, } \\
\text { G P Jotz, } \\
\text { M C Barba, } \\
\text { P G M Demeneghi, } \\
\text { C H P Mello - } \\
2009\end{array}$ & $\begin{array}{l}\text { Effectiveness of a } \\
\text { Program of Auditory } \\
\text { Prothetization in } \\
\text { Elders Through the } \\
\text { Application of HHIE-S } \\
\text { Questionnaire }\end{array}$ & $\begin{array}{l}\text { Avaliar o impacto } \\
\text { subjetivo de um } \\
\text { programa de reabilitação } \\
\text { auditiva em um grupo de } \\
\text { idosos. }\end{array}$ & $\begin{array}{l}\text { Aplicação do questionário } \\
\text { HHIE-S em } 47 \text { idosos, } \\
\text { antes e } 30 \text { dias depois } \\
\text { das terapias de } \\
\text { reabilitação auditiva. }\end{array}$ & $\begin{array}{l}\text { O impacto negativo da } \\
\text { deficiência auditiva nos } \\
\text { sujeitos caiu de } 24,2 \text { para } 1,8, \\
\text { antes e depois da reabilitação, } \\
\text { respectivamente. Entretanto, } \\
\text { pesquisas após } 6 \text { ou } 12 \text { meses } \\
\text { verificariam esse índice com } \\
\text { mais confiabilidade. }\end{array}$ \\
\hline $\begin{array}{l}\text { G C Gouveia, W V } \\
\text { Souza, } \\
\text { C F Luna, } \\
\text { P R B } \\
\text { Souza-Júnior, } \\
\text { C L Szwarcwald - } \\
2009\end{array}$ & \begin{tabular}{|l} 
Satisfação dos \\
usuários do sistema \\
de saúde brasileiro: \\
fatores associados e \\
diferenças regionais
\end{tabular} & $\begin{array}{l}\text { Avaliar os fatores } \\
\text { associados à satisfação, } \\
\text { bem como as diferenças } \\
\text { regionais do grau de } \\
\text { satisfação dos usuários } \\
\text { do sistema de saúde } \\
\text { brasileiro. }\end{array}$ & $\begin{array}{l}\text { Análise de dados } \\
\text { provenientes das } \\
\text { pesquisas PMS brasileira } \\
\text { e PMS-AB realizada } \\
\text { em Pernambuco. } \\
\text { As perguntas se } \\
\text { referiam a acesso ao } \\
\text { serviço, postura dos } \\
\text { profissionais, estrutura } \\
\text { das instalações do } \\
\text { serviço e equipamentos } \\
\text { e medicamentos } \\
\text { disponíveis. As respostas } \\
\text { do questionário foram } \\
\text { relacionadas com } \\
\text { dados sócio-econômico- } \\
\text { demográficos dos } \\
\text { sujeitos. }\end{array}$ & $\begin{array}{l}\text { - Ser jovem, usuário exclusivo } \\
\text { do SUS, ter baixa escolaridade } \\
\text { e autopercepção de saúde } \\
\text { ruim gerou mais chances de } \\
\text { insatisfação; } \\
\text { - Indivíduos residentes } \\
\text { na Região Sul do país } \\
\text { apresentam maiores chances } \\
\text { de se sentirem satisfeitos } \\
\text { com o atendimento em } \\
\text { saúde comparados aos } \\
\text { nordestinos, em especial os } \\
\text { pernambucanos. }\end{array}$ \\
\hline
\end{tabular}




\begin{tabular}{|c|c|c|c|c|}
\hline Autor e ano & Título & Objetivo & Metodologia & Resultados Principais \\
\hline $\begin{array}{l}\text { M A Esperidião, } \\
\text { L A B Trad - } 2006\end{array}$ & $\begin{array}{l}\text { Avaliação de } \\
\text { satisfação de } \\
\text { usuários: } \\
\text { considerações } \\
\text { teórico-conceituais }\end{array}$ & $\begin{array}{l}\text { Desenvolver uma } \\
\text { análise crítica da } \\
\text { produção científica sobre } \\
\text { o tema da satisfação de } \\
\text { usuários de serviços de } \\
\text { saúde. }\end{array}$ & $\begin{array}{l}\text { Artigo de revisão. Foram } \\
\text { analisados } 56 \text { artigos } \\
\text { publicados especialmente } \\
\text { em revistas indexadas } \\
\text { pelo MEDLINE e Web of } \\
\text { Science no período de } \\
1970 \text { a } 2005 .\end{array}$ & $\begin{array}{l}\text { - Os conceitos empregados } \\
\text { nas avaliações em saúde têm } \\
\text { origem no marketing e na } \\
\text { psicologia social; } \\
\text { - Não existe referencial teórico } \\
\text { estável sobre satisfação em } \\
\text { saúde; } \\
\text { - A categoria necessidade } \\
\text { muitas vezes é esquecida; } \\
\text { - Há uma valorização da } \\
\text { categoria expectativa, que } \\
\text { pode traduzir uma visão } \\
\text { idealizada pelo usuário. }\end{array}$ \\
\hline $\begin{array}{l}\text { A M Arakawa, } \\
\text { et al. - } 2010\end{array}$ & $\begin{array}{l}\text { A Avaliação da } \\
\text { Satisfação dos } \\
\text { Usuários de AASI na } \\
\text { Região Amazônica }\end{array}$ & $\begin{array}{l}\text { Avaliar o nível de } \\
\text { satisfação dos usuários } \\
\text { de aparelho de } \\
\text { amplificação sonora } \\
\text { individual (AASI). }\end{array}$ & $\begin{array}{l}\text { Estudo prospectivo } \\
\text { com } 18 \text { indivíduos com } \\
\text { deficiência auditiva, } \\
\text { adaptados com AASI } \\
\text { na Clínica de Saúde } \\
\text { Bucal e Fonoaudiológica } \\
\text { de Monte Negro/RO. } \\
\text { Para a avaliação foi } \\
\text { utilizado o questionário } \\
\text { de auto-avaliação IOI-HA } \\
\text { (International Outcome } \\
\text { Inventory for Hearing } \\
\text { Aids), aplicado } 3 \text { meses } \\
\text { após a adaptação do } \\
\text { AASI. }\end{array}$ & $\begin{array}{l}\text { A questão referente à } \\
\text { satisfação do usuário com } \\
\text { o AASI foi a mais pontuada, } \\
\text { enquanto a questão sobre } \\
\text { dificuldade residual de } \\
\text { comunicação, mesmo com } \\
\text { o uso do AASI, foi a menos } \\
\text { pontuada. O estudo constatou } \\
\text { que os usuários se encontram } \\
\text { satisfeitos com a adaptação. } \\
\text { O questionário foi de fácil } \\
\text { aplicação. }\end{array}$ \\
\hline $\begin{array}{l}\text { M Esperidião, } \\
\text { L A B Trad - } 2005\end{array}$ & $\begin{array}{l}\text { Avaliação de } \\
\text { satisfação de } \\
\text { usuários }\end{array}$ & $\begin{array}{l}\text { Apresentar as } \\
\text { considerações } \\
\text { metodológicas } \\
\text { formuladas na literatura } \\
\text { sobre a satisfação de } \\
\text { usuários, evidenciando } \\
\text { as principais abordagens } \\
\text { disponíveis, discutindo } \\
\text { seus limites e } \\
\text { possibilidades. }\end{array}$ & $\begin{array}{l}\text { Artigo de revisão, com } \\
\text { síntese qualitativa dos } \\
\text { estudos voltados para a } \\
\text { análise metodológica das } \\
\text { avaliações de satisfação } \\
\text { de usuários com serviços } \\
\text { de saúde. Foram } \\
\text { analisados } 54 \text { artigos } \\
\text { publicados em revistas } \\
\text { indexadas pelo Medline } \\
\text { e Web of Science no } \\
\text { período de } 1970 \text { a } 2005 \text {. }\end{array}$ & $\begin{array}{l}\text { - Não há ainda metodologia de } \\
\text { avaliação válida e confiável; } \\
\text { - Uma combinação de } \\
\text { métodos poderia ser uma } \\
\text { boa estratégia para evitar } \\
\text { reducionismos de cada método } \\
\text { isolado; } \\
\text { - As pesquisas no Brasil } \\
\text { devem se adequar à realidade } \\
\text { da população; } \\
\text { - Deve-se distinguir avaliação } \\
\text { de serviços públicos e } \\
\text { privados. }\end{array}$ \\
\hline $\begin{array}{l}\text { L R Veiga, } \\
\text { Á R C Merlo, } \\
\text { S S Mengue- } \\
2005\end{array}$ & $\begin{array}{l}\text { Satisfação com a } \\
\text { prótese auditiva } \\
\text { na vida diária em } \\
\text { usuários do sistema } \\
\text { de saúde do Exército }\end{array}$ & $\begin{array}{l}\text { Investigar o nível de } \\
\text { satisfação com a prótese } \\
\text { auditiva na vida diária } \\
\text { em usuários do Sistema } \\
\text { de Saúde do Exército e } \\
\text { fatores associados. }\end{array}$ & \begin{tabular}{|l|} 
Estudo transversal com \\
201 usuários de próteses \\
auditivas adquiridas \\
pelo convênio do Fundo \\
de Saúde do Exército \\
(FUSEX), entre 1998 e \\
2003. A avaliação da \\
satisfação com o uso da \\
prótese auditiva \\
na vida diária foi realizada \\
por meio do questionário \\
Satisfaction With \\
Amplification in Daily Life \\
- SADL. \\
\end{tabular} & $\begin{array}{l}\text { - Os pacientes estavam } \\
\text { consideravelmente satisfeitos } \\
\text { com o uso da prótese auditiva; } \\
\text { - Houve menor satisfação na } \\
\text { subescala fatores negativos } \\
\text { do SADL, especialmente em } \\
\text { relação ao uso do telefone; } \\
\text { - Tiveram associação com a } \\
\text { satisfação fatores ligados à } \\
\text { pessoa e, principalmente, à } \\
\text { reabilitação auditiva. }\end{array}$ \\
\hline
\end{tabular}




\begin{tabular}{|c|c|c|c|c|}
\hline Autor e ano & Título & Objetivo & Metodologia & Resultados Principais \\
\hline $\begin{array}{l}\text { R B Farias, } \\
\text { I C P Russo - } \\
2010\end{array}$ & $\begin{array}{l}\text { Saúde auditiva: } \\
\text { estudo do grau } \\
\text { de satisfação de } \\
\text { usuários de aparelho } \\
\text { de amplificação } \\
\text { sonora individual }\end{array}$ & $\begin{array}{l}\text { Caracterizar o grau de } \\
\text { satisfação em adultos } \\
\text { e idosos usuários } \\
\text { de aparelhos de } \\
\text { amplificação sonora } \\
\text { individual (AASI) } \\
\text { atendidos em serviços } \\
\text { públicos de saúde } \\
\text { auditiva e sua relação } \\
\text { com as variáveis } \\
\text { gênero, idade, grau } \\
\text { da perda auditiva, tipo } \\
\text { e perfil eletroacústico } \\
\text { do AASI, comparando } \\
\text { os resultados com } \\
\text { os dados normativos } \\
\text { estabelecidos pelas } \\
\text { autoras do questionário. }\end{array}$ & $\begin{array}{l}39 \text { indivíduos, na faixa } \\
\text { etária entre } 18 \text { e } 90 \\
\text { anos, foram avaliados } \\
\text { por meio do questionário } \\
\text { Satisfaction with } \\
\text { Amplification in Daily } \\
\text { Life - SADL, cuja } \\
\text { aplicação foi realizada por } \\
\text { meio de apresentação } \\
\text { oral, em entrevistas } \\
\text { individuais, pelo próprio } \\
\text { pesquisador. }\end{array}$ & $\begin{array}{l}\text { - Todos os indivíduos } \\
\text { entrevistados apresentaram } \\
\text { um grau de satisfação com } \\
\text { o uso do AASI maior do } \\
\text { que aquele encontrado na } \\
\text { normatização estabelecida } \\
\text { em todas as categorias do } \\
\text { questionário; } \\
\text { - Observou-se associação } \\
\text { estatisticamente significante } \\
\text { quanto ao grau de satisfação } \\
\text { relacionado ao tipo de AASI } \\
\text { utilizado. }\end{array}$ \\
\hline
\end{tabular}

Figura 2 - Quadro resumo com os artigos do eixo temático Usuários 
Na Figura 3 estão descritos os artigos relacionados ao eixo temático: Profissionais. Todos os artigos têm como temática a capacitação de profissionais de saúde em saúde auditiva ${ }^{18-20}$.

\begin{tabular}{|c|c|c|c|c|}
\hline Autor e ano & Título & Objetivo & Metodologia & Resultados Principais \\
\hline $\begin{array}{l}\text { K F Alvarenga, } \\
\text { M C Bevilacqua, } \\
\text { M A N S Martinez, } \\
\text { T M Melo, } \\
\text { W Q Blasca, } \\
\text { M F L Taga - } \\
2008\end{array}$ & $\begin{array}{l}\text { Proposta para } \\
\text { capacitação de agentes } \\
\text { comunitários de saúde } \\
\text { em saúde auditiva }\end{array}$ & $\begin{array}{l}\text { Verificar a efetividade } \\
\text { de um programa de } \\
\text { capacitação de agentes } \\
\text { comunitários de saúde } \\
\text { do Programa de Saúde } \\
\text { da Família, na área de } \\
\text { saúde auditiva infantil. }\end{array}$ & $\begin{array}{l}\text { Os } 2 \text { grupos do estudo } \\
\text { foram capacitados } \\
\text { por meio de aulas } \\
\text { expositivas, porém o } \\
\text { grupo A utilizou a apostila } \\
\text { adaptada da World } \\
\text { Health Organization } \\
\text { (2006). Foi aplicado } \\
\text { questionário pré e pós } \\
\text { capacitação. }\end{array}$ & $\begin{array}{l}\text { A capacitação foi efetiva } \\
\text { para ambos os grupos. } \\
\text { Grupo A registrou diferença } \\
\text { estatisticamente significante } \\
\text { em todos os aspectos da } \\
\text { capacitação, enquanto o } \\
\text { grupo B apenas no aspecto } \\
\text { prevenção. }\end{array}$ \\
\hline $\begin{array}{l}\text { T M Melo, } \\
\text { K F Alvarenga, } \\
\text { W Q Blasca, } \\
\text { M F L Taga-- } \\
2010\end{array}$ & \begin{tabular}{|l} 
Capacitação de \\
agentes comunitários \\
de saúde em saúde \\
auditiva: efetividade da \\
videoconferência
\end{tabular} & $\begin{array}{l}\text { Avaliar a efetividade } \\
\text { da capacitação dos } \\
\text { Agentes Comunitários } \\
\text { de Saúde (ACS), } \\
\text { por meio da } \\
\text { videoconferência, na } \\
\text { área de saúde auditiva } \\
\text { infantil. }\end{array}$ & $\begin{array}{l}50 \text { profissionais divididos } \\
\text { em dois grupos: } 31 \\
\text { capacitados de forma } \\
\text { presencial e } 19 \text { por meio } \\
\text { de videoconferência. } \\
\text { Foram ministradas aulas } \\
\text { expositivas utilizando } \\
\text { o material adaptado } \\
\text { Primary ear and hearing } \\
\text { care training resource, de } \\
\text { forma simultânea para } \\
\text { ambos os grupos. Por } \\
\text { meio de questionário, } \\
\text { comparou-se resultados } \\
\text { de antes e depois da } \\
\text { capacitação. }\end{array}$ & $\begin{array}{l}\text { Ambos os grupos } \\
\text { apresentaram diferença } \\
\text { estatisticamente significante no } \\
\text { desempenho apresentado no } \\
\text { instante pré e pós-capacitação, } \\
\text { porém de forma mais } \\
\text { expressiva para o grupo que } \\
\text { participou da capacitação de } \\
\text { forma presencial. }\end{array}$ \\
\hline $\begin{array}{l}\text { T M Melo, } \\
\text { K F Alvarenga - } \\
2009\end{array}$ & $\begin{array}{l}\text { Capacitação de } \\
\text { profissionais da saúde } \\
\text { na área de saúde } \\
\text { auditiva: revisão } \\
\text { sistemática }\end{array}$ & $\begin{array}{l}\text { Avaliar a capacitação } \\
\text { de profissionais da } \\
\text { saúde sobre saúde } \\
\text { auditiva por meio de } \\
\text { revisão sistemática. }\end{array}$ & $\begin{array}{l}\text { Artigo de revisão. } \\
\text { Pergunta: "Qual } \\
\text { a efetividade da } \\
\text { capacitação de } \\
\text { profissionais da saúde, } \\
\text { para atuarem na área } \\
\text { de saúde auditiva?". } \\
\text { Foram levados em conta } \\
\text { os aspectos tipo de } \\
\text { estudo, participantes, } \\
\text { intervenção adotada e } \\
\text { avaliação dos resultados } \\
\text { para seleção dos artigos. } \\
\text { Como resultado, cinco } \\
\text { estudos foram incluídos } \\
\text { na revisão sistemática. }\end{array}$ & $\begin{array}{l}\text { A capacitação dos profissionais } \\
\text { em saúde auditiva é efetiva, } \\
\text { aumentando o conhecimento } \\
\text { desses sujeitos sobre o } \\
\text { tema. Dessa forma, os } \\
\text { processos de identificação } \\
\text { e encaminhamento dos } \\
\text { indivíduos com sinais de } \\
\text { distúrbios auditivos para os } \\
\text { serviços de referência são } \\
\text { feitos com maior facilidade. }\end{array}$ \\
\hline
\end{tabular}

Figura 3 - Quadro resumo com os artigos do eixo temático Profissionais 
Na Figura 4 estão descritos os artigos relacionados ao eixo temático Serviço. Nota-se grande variedade na temática dos artigos dessa categoria, desde oferta de serviços ${ }^{21}$ à criação de indicadores em saúde auditiva ${ }^{22}$.

\begin{tabular}{|c|c|c|c|c|}
\hline Autor e ano & Título & Objetivo & \begin{tabular}{|l|} 
Metodologia \\
\end{tabular} & Resultados Principais \\
\hline $\begin{array}{l}\text { D R Lewis, } \\
\text { S A M Marone, } \\
\text { B C A Mendes, } \\
\text { O L M Cruz, } \\
\text { M Nóbrega - } \\
2010\end{array}$ & $\begin{array}{l}\text { Comitê } \\
\text { multiprofissional } \\
\text { em saúde auditiva } \\
\text { COMUSA }\end{array}$ & $\begin{array}{l}\text { O artigo traz uma breve } \\
\text { descrição do COMUSA } \\
\text { e divulga um parecer } \\
\text { sobre a TANU, de forma } \\
\text { a nortear as ações dos } \\
\text { profissionais envolvidos. }\end{array}$ & $\begin{array}{l}\text { Os autores fazem uma } \\
\text { breve revisão da atual } \\
\text { situação da TANU tanto } \\
\text { no Brasil quanto em } \\
\text { outros países que a } \\
\text { realizam. Em seguida, } \\
\text { divulgam as atuais } \\
\text { recomendações da } \\
\text { organização. }\end{array}$ & $\begin{array}{l}\text { A organização lança } 21 \\
\text { recomendações a respeito dos } \\
\text { procedimentos para a realização } \\
\text { da TANU e das instalações dos } \\
\text { locais credenciados. }\end{array}$ \\
\hline $\begin{array}{l}\text { C Barreira- } \\
\text { Nielsen, } \\
\text { H A F Neto, } \\
\text { G Gattaz - } \\
2007\end{array}$ & \begin{tabular}{|l} 
Processo de \\
implantação de \\
Programa de Saúde \\
Auditiva em duas \\
maternidades \\
públicas
\end{tabular} & $\begin{array}{l}\text { Apresentar os resultados } \\
\text { do processo de } \\
\text { implantação de um } \\
\text { programa de saúde } \\
\text { auditiva neonatal } \\
\text { em serviço público e } \\
\text { revisar os aspectos } \\
\text { determinantes } \\
\text { no planejamento, } \\
\text { efetividade, manutenção } \\
\text { e aprimoramento. } \\
\end{array}$ & $\begin{array}{l}\text { Foram avaliados os } \\
\text { aspectos capacitação de } \\
\text { equipe, ambiente de teste } \\
\text { (ruído e indivíduo), falso- } \\
\text { negativo, evasão e tempo } \\
\text { de exame, por meio de } \\
\text { questionário aplicado nos } \\
\text { profissionais das equipes } \\
\text { de saúde e extração de } \\
\text { dados de prontuários e } \\
\text { exames. }\end{array}$ & $\begin{array}{l}\text { São necessários protocolos } \\
\text { com o critério passa-falha para } \\
\text { cada um dos procedimentos; é } \\
\text { preciso que se tenha uma agenda } \\
\text { organizada para as marcações } \\
\text { dos exames e acompanhamentos } \\
\text { das crianças com risco; é crucial } \\
\text { o treinamento das equipes de } \\
\text { saúde sobre saúde auditiva; a } \\
\text { realização da triagem não deve } \\
\text { se limitar às maternidades. }\end{array}$ \\
\hline $\begin{array}{l}\text { M C Bevilacqua, } \\
\text { M Melo, } \\
\text { M Morettin, } \\
\text { A C Lopes - } 2009\end{array}$ & $\begin{array}{l}\text { A avaliação de } \\
\text { serviços em } \\
\text { Audiologia: } \\
\text { concepções e } \\
\text { perspectivas }\end{array}$ & $\begin{array}{l}\text { Abordar alguns conceitos } \\
\text { teóricos acerca da } \\
\text { avaliação e indicadores } \\
\text { de qualidade dos } \\
\text { serviços de saúde, bem } \\
\text { como contextualizar o } \\
\text { atual panorama desta } \\
\text { temática frente aos } \\
\text { serviços de saúde } \\
\text { auditiva do Sistema } \\
\text { Único de Saúde (SUS). }\end{array}$ & $\begin{array}{l}\text { Artigo de revisão. } \\
\text { Levantamento } \\
\text { bibliográfico conduzido } \\
\text { nas bases eletrônicas de } \\
\text { dados de acesso público, } \\
\text { tais como: LILACS, } \\
\text { Medline e SciELO; sem } \\
\text { restrição no ano de } \\
\text { publicação. Como o foco } \\
\text { do presente estudo é a } \\
\text { avaliação de serviços no } \\
\text { âmbito do SUS, foram } \\
\text { priorizados trabalhos } \\
\text { desenvolvidos em nível } \\
\text { nacional. }\end{array}$ & $\begin{array}{l}\text { - A avaliação da qualidade dos } \\
\text { serviços de saúde deve abordar } \\
\text { os seguimentos da estrutura, do } \\
\text { processo e dos resultados da } \\
\text { intervenção; } \\
\text { - A fonte utilizada para analisar o } \\
\text { indicador devem ser os gestores, } \\
\text { os profissionais e os pacientes } \\
\text { que utilizam os serviços; } \\
\text { - Os indicadores devem ser } \\
\text { diferenciados para cada grupo; } \\
\text { - É necessária a definição de um } \\
\text { nível básico de qualidade para } \\
\text { um bom atendimento ao paciente } \\
\text { e a otimização da verba pública } \\
\text { aplicada nestes serviços para } \\
\text { todas as regiões. }\end{array}$ \\
\hline $\begin{array}{l}\text { G M D Miranda, } \\
\text { B A M Queiroga, } \\
\text { F J D Lessa, } \\
\text { M C Leal, } \\
\text { S S C Neto - } \\
2006\end{array}$ & $\begin{array}{l}\text { Diagnóstico da } \\
\text { deficiência auditiva } \\
\text { em Pernambuco: } \\
\text { oferta de serviços } \\
\text { de média } \\
\text { complexidade - } \\
2003\end{array}$ & $\begin{array}{l}\text { Estudar a oferta de } \\
\text { serviços de diagnóstico } \\
\text { da Deficiência Auditiva } \\
\text { na média complexidade } \\
\text { em Pernambuco no } 1^{\circ} \\
\text { semestre de } 2003 .\end{array}$ & \begin{tabular}{|l|} 
Foram estudados os \\
arquivos de produção \\
ambulatorial e de \\
atividade profissional \\
dos municípios de \\
Pernambuco, disponíveis \\
no Sistema de \\
Informação Ambulatorial \\
do Ministério da Saúde.
\end{tabular} & $\begin{array}{l}\text { Os procedimentos de diagnóstico } \\
\text { de deficiência auditiva estão } \\
\text { sendo realizados apenas em } 5 \\
\text { municípios do Estado, sendo que } \\
19 \text { são classificados como média } \\
\text { complexidade; a esfera municipal } \\
\text { é responsável por mais da } \\
\text { metade dos procedimentos; } 63 \% \\
\text { dos municípios não possuem } \\
\text { nenhum profissional capacitado } \\
\text { para o diagnóstico auditivo. }\end{array}$ \\
\hline $\begin{array}{l}\text { L A R Rossi- } \\
\text { Barbosa, } \\
\text { S M F V Vieira, } \\
\text { C R T Manzoni, } \\
\text { A P Caldeira, } \\
\text { R Honorato- } \\
\text { Marques, } \\
\text { J A Ribeiro, } \\
\text { R F Silva - } 2010\end{array}$ & $\begin{array}{l}\text { Processo de } \\
\text { construção de } \\
\text { indicadores em } \\
\text { saúde auditiva }\end{array}$ & $\begin{array}{l}\text { Avaliar a adequação } \\
\text { de um instrumento, } \\
\text { que está em fase de } \\
\text { implantação, elaborado } \\
\text { pela Secretaria Municipal } \\
\text { de Saúde de São Paulo } \\
\text { quanto ao serviço de } \\
\text { saúde e uso da prótese } \\
\text { auditiva. }\end{array}$ & $\begin{array}{l}\text { Instrumento composto } \\
\text { por } 17 \text { perguntas que } \\
\text { avaliam o serviço e a } \\
\text { satisfação do usuário. Foi } \\
\text { aplicado em } 17 \text { sujeitos, } \\
\text { com idades entre } 21 \text { a } 91 \\
\text { anos. }\end{array}$ & $\begin{array}{l}\text { A maioria dos entrevistados } \\
\text { relatou alguma dificuldade no } \\
\text { uso do AASI e classificaram } \\
\text { sua satisfação com o serviço } \\
\text { e com o uso do AASI como } \\
\text { regular. Deve-se reformular e } \\
\text { reavaliar o instrumento, com um } \\
\text { número maior de sujeitos, para } \\
\text { reformular/ acrescentar questões } \\
\text { referentes aos dois aspectos } \\
\text { propostos a avaliação. }\end{array}$ \\
\hline
\end{tabular}

Figura 4 - Quadro resumo com os artigos do eixo temático Serviço 
A pesquisa para o estudo buscou artigos do período entre os anos 2000 e 2010, entretanto somente foram encontradas publicações a partir do ano de 2005.

No ano de 2005 foram identificados dois artigos que abordavam a questão da avaliação, sendo esta a primeira temática encontrada. Uma das publicações é um artigo de revisão que investiga as bases metodológicas para o processo de avaliação de serviços de saúde com base na satisfação do usuário ${ }^{9}$. O segundo é um estudo transversal que avalia a satisfação e adaptação do usuário de AASI por meio de um questionário ${ }^{10}$. Deve-se destacar que nesse caso o enfoque da avaliação é na satisfação do usuário em relação a um aspecto específico do serviço (o benefício do recebimento do AASI) e não ao serviço quanto à organização e gestão. Em 2005 a Saúde Auditiva ainda era um programa recente, o que explica o surgimento do interesse por sua avaliação.

No ano de 2006 a satisfação do usuário é abordada novamente por meio de um artigo de revisão ${ }^{11}$. Esse trabalho constata que a satisfação em saúde é muitas vezes abordada em questionários para avaliar o serviço, porém não existe um referencial teórico consistente sobre esse aspecto, que é de cunho subjetivo. Além disso, segundo os autores, os conceitos empregados nas avaliações em saúde, baseados na satisfação do usuário, tem origem no marketing e na psicologia social, o que por vezes não se mostra como uma referência adequada para a especificidade das ações e serviços de saúde. A outra publicação do ano de 2006 trata de um aspecto da gestão do serviço, abordando uma temática nova: a oferta de serviços de saúde auditiva ${ }^{21}$. $\mathrm{O}$ trabalho traz um diagnóstico do serviço no estado de Pernambuco, mostrando a realidade enfrentada nos serviços credenciados, concluindo que ainda é preciso mais investimentos na estrutura dos serviços e cumprimento rigoroso da Política de Atenção à Saúde Auditiva.

A gestão do serviço é novamente explorada em 2007, por meio de um artigo que retrata a implantação do Programa de Saúde Auditiva em duas maternidades públicas ${ }^{23}$. Com essa pesquisa, pôde-se verificar a que aspectos o Programa estava adequado ou inadequado, buscando soluções para as falhas encontradas, tendo como exemplos a falta de organização da agenda para marcação de exames e acompanhamento das crianças de risco, a necessidade de treinamento das equipes de saúde e a atual limitação da realização da triagem auditiva somente em maternidades.

Uma nova temática passa a ser abordada no ano de 2008: a capacitação dos profissionais de saúde em saúde auditiva ${ }^{18}$. A Política de Atenção à Saúde
Auditiva abrange os três níveis de complexidade do sistema de saúde brasileiro e, com essa publicação, passa-se a ter um olhar mais direcionado à atenção básica, peça chave nesse programa. Com a capacitação dos Agentes Comunitários de Saúde (ACS) torna-se possível o diagnóstico precoce de problemas auditivos, o que antes acontecia tardiamente e o indivíduo, por vezes, já apresentava um problema em estágio avançado.

No ano de 2009 há um aumento do número de publicações encontradas. Alguns temas continuam a ser abordados, como a avaliação do serviço de saúde auditiva ${ }^{2}$, a satisfação do usuário ${ }^{12-14}$ e a capacitação dos profissionais de saúde ${ }^{19}$. Entretanto, surge uma nova temática: o acesso do usuário ao serviç $0^{5,6}$. Dois artigos exploram esse tema no mesmo cenário: a Rede de Atenção Básica. Um deles apenas descreve as dificuldades de acesso enfrentadas pelo sujeito deficiente auditivo ${ }^{5}$. $O$ outro faz uma comparação entre o acesso das pessoas com e sem a deficiência auditiva ${ }^{6}$. A grande diferença entre as duas publicações são os pontos de vista apresentados: a primeira aborda a posição do gestor, gerentes de unidades básicas de saúde; a segunda retrata o olhar do usuário.

O grande número de artigos publicados se mantém em 2010, assim como a variedade dos temas abordados. Aparecem pela primeira vez artigos sobre o perfil dos usuários ${ }^{7,8}$, trazendo descrições socioeconômicas, demográficas e das perdas auditivas de sujeitos atendidos em serviços credenciados. Outro tema inédito é a construção de indicadores de saúde em saúde auditiva ${ }^{22}$, por meio de questionário sobre o serviço. A avaliação do serviço pelos usuários ${ }^{15-17}$ permanece como tema recorrente, refletindo a importância de se acompanhar o andamento da Política de Atenção a Saúde Auditiva.

Nota-se que com o passar do tempo o número de publicações vem aumentando, o que mostra que a saúde auditiva tem ganhado reconhecimento dentro da saúde pública. A variedade de temas abordados e a época em que cada um deles surge podem ser consideradas indicadores dos marcos alcançados pela Política de Atenção à Saúde Auditiva ao longo dos anos.

Diferentes temas são abordados no eixo Usuários. O maior número de artigos se refere ao tema avaliação. Dentro desse tema, artigos que enfocam a satisfação do usuário é maioria. Acesso do usuário ao serviço e descrição do perfil da população atendida são os outros temas encontrados. Dos 13 artigos, apenas dois são revisões de literatura ${ }^{9,11}$. A metodologia mais utilizada foi a aplicação de questionários nos sujeitos participantes das pesquisas. 
Os artigos do eixo temático Profissionais abordam um mesmo tema: a capacitação de profissionais da saúde em saúde auditiva. Entretanto, os assuntos são diversificados. Encontrou-se um artigo de revisão ${ }^{15}$ e dois originais de pesquisa ${ }^{18,20}$. Os três artigos abordam diferentes metodologias de capacitação dos profissionais da saúde e analisam a efetividade desses métodos.

Os temas dos artigos referentes ao eixo Serviço são muito diversificados; foram cinco artigos encontrados e quatro diferentes temas. Apenas um artigo trata de revisão de literatura ${ }^{2}$. Com exceção deste, todos os artigos desse eixo temático abordam a avaliação de serviços fora do âmbito da atenção básica ${ }^{21,23,24}$. Destes quatro, apenas um artigo dá enfoque à visão do usuário 22 .

Ao estabelecer uma relação entre os três eixos temáticos, é possível fazer algumas constatações. Em relação ao número de artigos, o eixo temático Usuários é o que apresenta maior quantidade. Esse eixo é também o que apresenta os artigos mais bem distribuídos em relação à cronologia, não sendo encontrada publicação com enfoque no usuário apenas no ano de 2007. Ainda, levando em conta o número de sujeitos de estudo de pesquisa, os artigos do eixo Serviço são os que apresentam casuística com o menos número de sujeitos.

Após a análise de todo o material compilado, pôde-se traçar um perfil das publicações. A maior parte das pesquisas foi realizada em estados da região centro-sul do país ${ }^{5-7,10,12,13,15,17,18,20,22,23}$. Entretanto, Pernambuco merece destaque, visto que três artigos foram produzidos no estado ${ }^{8,14,21}$. O tema mais recorrente entre as publicações é a avaliação dos serviços. Artigos que abordam esse tema são encontrados em dois eixos temáticos, Usuários e Serviço. Apesar de compartilharem o mesmo tema, os artigos dos eixos Usuários e Serviço se diferem pelo ponto de vista predominantemente abordado, usuários e gestores, respectivamente.

O presente estudo se propôs a fazer um compilado da literatura na área de saúde auditiva e discutir o conteúdo e perfil das publicações, o que nos permitiu construir uma visão global da produção científica em saúde auditiva. A análise dos artigos selecionados estabeleceu uma articulação entre três eixos fundamentais para o processo de cuidado em saúde, de modo a formar a tríade: Profissionais, Serviço e Usuários. Essa interrelação construída entre os artigos pode ser vista com um avanço trazido pelo presente estudo para a análise do estado da arte em saúde auditiva. Entretanto, a escolha dos três eixos temáticos aqui discutidos limitou o número de artigos selecionados para o estudo, visto que artigos relacionados a outros temas não puderam ser incluídos. Outra limitação do estudo é a inclusão apenas de artigos nacionais. Porém, essa limitação é justificada pelo falto de o eixo central da pesquisa ser a Política Nacional de Atenção à Saúde Auditiva, o que faz com que somente artigos relacionados ao Sistema de Saúde Brasileiro sejam relevantes ao estudo.

\section{CONCLUSÃO}

Por meio da análise da produção científica, pôde-se observar que a maioria dos estudos concentra-se na região centro-sul do país e que o tema mais abordado refere-se à avaliação dos serviços. O eixo temático com maior número de artigos relacionados foi Usuários.

Nota-se que os temas abordados pelos estudos, bem como os anos de publicação, evidenciam os marcos alcançados pela Política Nacional de Atenção à Saúde Auditiva. O foco das primeiras publicações era a satisfação do usuário, o que refletia a importância dada à visão desse sujeito. Com o passar do tempo, outros pontos do Programa foram ganhando destaque, fazendo com que surgissem novos temas, abordando outras visões. Um desses pontos, que pode ser considerado o ponto chave, foi o crescimento do Programa ao longo dos anos, que passou a credenciar maior número de serviços para atender à demanda populacional. Daí surge o interesse pelas questões voltadas para a gestão e a necessidade de constante avaliação dos serviços e da capacitação de profissionais de saúde. Esse último tema reforça o destaque dado pela Política à Atenção Básica. 


\section{ABSTRACT}

The theme of this study is the analysis of the state of art in hearing health in Brazil and the investigation of scientific production in this area. The aim is to describe, to analyze and to build the story line of scientific hearing health in Brazil during the period between 2000 and 2010; the reference were the deployment, development and evaluation of hearing health policy of the Sistema Único de Saúde (SUS). The first studies are from 2005. Since then, especially in the two last years, the number of studies grew gradually. The category Users was the one with more articles included. The theme evaluation, focusing on users' satisfaction, was the most explored, followed by management and enablement of health professionals.

KEYWORDS: Public Health; Health Policy; Hearing

\section{REFERÊNCIAS}

1. Brasil. Ministério da Saúde. Portaria no 2.073/ GM, 28 de setembro de 2004. Institui a Política Nacional de Atenção à Saúde Auditiva. Brasília: MS, 2004. Disponível em: <http://dtr2001.saude. gov.br/sas/PORTARIAS/Port2004/GM/GM-2073. htm>. Acesso em 27 out. 2011.

2. Bevilacqua MC, Melo TM, Morettin M, Lopes AC. A avaliação de serviços em Audiologia: concepções e perspectivas. Rev Soc Bras Fonoaudiol. 2009;14(3):421-6.

3. Brasil. Ministério da Saúde. Portaria n0 587, de 7 de outubro de 2004. Disponível em: <http://dtr2001. saude.gov.br/sas/PORTARIAS/Port2004/PT-587. htm>. Acesso em 27 out. 2011.

4. Brasil. Ministério da Saúde. Portaria no 587, de 7 de outubro de 2004. Disponível em: <http://dtr2001. saude.gov.br/sas/PORTARIAS/Port2004/PT-589. $\mathrm{htm}>$. Acesso em 27 out.2011.

5. Ianni A, Pereira PCA. Acesso da comunidade surda à rede básica de saúde. Saúde e Sociedade. 2009;18(2):89-92.

6. Freire DB, Gigante LP, Béria JU, Palazzo LS, Figueiredo ACL, Raymann BCW. Acesso de pessoas deficientes auditivas a serviços de saúde em cidade do sul do Brasil. Cad. Saúde Pública. 2009;25(4):889-97.

7. Santos FR, Manfredi AKS, Isaac ML. Caracterização da perda auditiva de crianças atendidas em um programa de saúde auditiva. Medicina. Ribeirão Preto. 2009;42(3):366-71.

8. Griz SMS, Barbosa CP, Silva ARA, Ribeiro MA, Menezes DC. Aspectos demográficos e socioeconômicos de mães atendidas em um programa de triagem auditiva neonatal. Rev Soc Bras Fonoaudiol. 2010;15(2):179-83.
9. Esperidião $M$, Trad LAB. Avaliação de satisfação de usuários. Ciência e Saúde Coletiva. 2005;10(Sup):303-12.

10. Veiga LR, Merlo ARC, Mengue SS. Satisfação com a prótese auditiva na vida diária em usuários do sistema de saúde do Exército. Rev Bras Otorrinolaringol. 2005;71(1):67-73.

11. Esperidião MA, Trad LAB. Avaliação de satisfação de usuários: considerações teórico-conceituais. Cad. Saúde Pública. 2006;22(6):1267-76.

12. Fialho IM, Bortoli D, Mendonça GG, Pagnosim DF, Scholze AS. Percepção de idosos sobre o uso de AASI concedido pelo Sistema Único de Saúde. Rev. CEFAC. 2009;11(2):338-44.

13. Angeli RD, Jotz GP, Barba MC, Demeneghi PGM, Mello CHP. Effectiveness of a Program of Auditory Prothetization in Elders Through the Application of HHIE-S Questionnaire. Intl. Arch. Otorhinolaryngol. 2009;13(3):277-80.

14. Gouveia GC, Souza WV, Luna CF, SouzaJúnior PRB, Szwacwald CL. Satisfação dos usuários do sistema de saúde brasileiro: fatores associados e diferenças regionais. Rev Bras Epidemiol. 2009;12(3): 281-96.

15. Armigliato ME, Prado DGA, Melo TM, Martinez MANS, Lopes AC, Amantini RCB et al. Avaliação de serviços de saúde auditiva sob a perspectiva do usuário: proposta de instrumento. Rev Soc Bras Fonoaudiol. 2010;15(1):32-9.

16. Arakawa AM, Picolini MM, Sitta El, Oliveira NA, Bassi AKZ, Bastos JRM et al. A Avaliação da Satisfação dos Usuários de AASI na Região Amazônica. Intl. Arch. Otorhinolaryngol. 2010;14(1):38-44.

17. Farias RB, Russo ICP. Saúde auditiva: estudo do grau de satisfação de usuários de aparelho de amplificação sonora individual. Rev Soc Bras Fonoaudiol. 2010;15(1):26-31. 
18. Alvarenga KF, Bevilacqua MC, Martinez MANS, Melo TM, Blasca WQ, Taga MFL. Proposta para capacitação de agentes comunitários de saúde em saúde auditiva. Pró-Fono Revista de Atualização Científica. 2008;20(3):171-6.

19. Melo TM, Alvarenga KF. Capacitação de profissionais da saúde na área de saúde auditiva: revisão sistemática. Rev Soc Bras Fonoaudiol. 2009;14(2):280-6.

20. Melo TM, Alvarenga KF, Blasca WQ, Taga MFL. Capacitação de agentes comunitários de saúde em saúde auditiva: efetividade da videoconferência. Pró-Fono Revista de Atualização Científica. 2010;22(2):139-44.

21. Miranda GMD, Queiroga BAM, Lessa FJD, Leal MC, Neto SSC. Diagnóstico da deficiência auditiva em Pernambuco: oferta de serviços de média complexidade - 2003. Rev Bras Otorrinolaringol. 2006;72(4):581-6.

22. Rossi-Barbosa LAR, Vieira SMFV, Manzoni CRT, Caldeira AP, Honorato-Marques R, Ribeiro JA et al. Processo de construção de indicadores em saúde auditiva. Rev CEFAC. 2010; Epub June 18.

23. Barreira-Nielsen C, Neto HAF, Gattaz G. Processo de implantação de Programa de Saúde Auditiva em duas maternidades públicas. Rev Soc Bras Fonoaudiol. 2007;12(2):99-105.

24. Lewis DR, Marone SAM, Mendes BCA, Cruz OLM, Nóbrega M. Comitê multiprofissional em saúde auditiva - COMUSA. Bras J Otorhinolaryngol. 2010;76(1):121-8.
http://dx.doi.org/10.1590/S1516-18462012005000089

RECEBIDO EM: 23/09/2011

ACEITO EM: 25/01/2012

Endereço para correspondência:

Kléber Rangel Silva

Rua Tremedal, 267, 804

Carlos Prates, Belo Horizonte - MG

CEP: 30710-180

E-mail: kleber.fono@yahoo.com.br
ERRATA:

Incluída a informação de Fonte de auxílio: Edital FAPEMIG 24/2009 - Fundação de Amparo à Pesquisa de Minas Gerais. 